\title{
AÇÃO POLÍTICA E PENSAMENTO DAS MULHERES NEGRAS NAS AMÉRICAS: UMA PERSPECTIVA SOBRE A DIÁSPORA AFRICANA
}

- SÔNIA BEATRIZ DOS SANTOS'

Resumo: 7 presente artiga reflete sobre uma perspectiva da história intelectual da diaspara negra a partir da ação política e do pensamento das mulheres negras nas Américas, frente às distintas dinâmicas saciais que têm marcada as experiências de opressãa deste grupo. E procura, ainda, apresentar diferentes experiências de enfrentamento das pracessas de subardinaçãa e explaraçãa destes grupas. É uma história marcada par genealogias, açães políticas, e a produção de conhecimentas. Com o objetivo de refletir sobre as questões apresentadas a artigo está dividida em duas partes. A primeira busca apresentar o que a história da Diáspara Africana nas Américas revela sobre as condiçães saciais das mulheres negras. Na segunda parte procuramos refletir sobre a perspectiva racial de gênero das mulheres negras nas Américas. E nas consideraçães finais, tecemos breve reflexão sabre a relevância da presença e açãa das mulheres afradescendentes no continente, através de suas açães políticas e produção de conhecimentos, e coma estas questões devem influenciar nossas agendas de pesquisa.

Palavras-chaves: mulheres negras; ação política; produção do conhecimenta; anti-racisma; anti-sexismo; diáspara africana nas Américas.

\section{Introdução}

$\mathrm{O}$ presente artigo busca refletir sobre uma perspectiva da história intelectual da diaspora negra a partir da ação política e do pensamento das mulheres negras ${ }^{2}$ nas Américas, como sujeitos políticos, frente às distintas 
dinâmicas sociais que têm marcada as experiências de opressão deste grupo. E procura, ainda, apresentar diferentes experiências de enfrentamento dos processos de subordinação e exploração destes grupos.

Esta história é marcada por três elementos fundamentais que caracterizam estes movimentos: as genealogias - um conjunto diverso de lideranças ativistas e/ou feministas que têm atuado em suas regiões de origem, e em alguns casos em âmbito transnacional, as ações políticas ancoradas no anti-racismo e anti-sexismo, e a produção e difusão de conhecimentos que emergem das lutas históricas empreendidas pelas mulheres afrodescendentes nas Américas. Deste modo, a partir destas três aspectos, é possível compreendermos a história da Diaspora Africana ${ }^{3}$ sob uma perspectiva feminina negra. Comecemos então, esta reflexão por entender o conceito de diaspora proposto, a partir da ótica de duas intelectuais - Ruth Hamilton e Marilise Reis.

HAMILTON (1990) em conjunto com sua equipe de pesquisadores associados da Universidade do Estado de Michigan definiu que:

A diáspora Africana representa um tipo de agrupamento social caracterizado por uma padronização histórica de determinadas relações sociais e experiências. Como uma formação social, é conceituada como uma agregação global de atores e subpopulações, diferenciados em termos de espaço social e geográfico, mas que ainda assim exibem um traço comum com base em fatores históricos, condicionados por e dentro do sistema da ordem mundial. Entre as características que distinguem a diáspora como uma formação global composta por outros grupos socialmente diferenciados estão as seguintes experiências históricas compartilhadas: Migração e Deslocamento Geo-Social: a circulação de pessoas; ... Opressão Social: relações de dominação e subordinação; $\quad$... Persistência, Resistência, e Luta: Ações Culturais e Políticas (WHITTEN JR, Norman E. and TORRES, Arlene Apud SIMMS HAMILTON 1990: 18).

A definição de Ruth Hamilton representa uma perspectiva de conceituar a ideia de diaspora. Já para REIS (2011) a,

Diáspora não pode mais ser entendida apenas como mero deslocamento físico, em sentido geográfico, isto é fato. De termo empregado como uma metáfora de deslocamentos e de desterritorializações que muda e amplia a própria noção de afastamento geográfico, passou também a designar 
um tipo de consciência, um modo de produção cultural, uma espécie de experiência intelectual e consciência identitária que perturba modelos fixos de identidade cultural (Hall, 2003). (p.1)

REIS também enfatiza que a Diáspora se constitui numa "espécie de laboratório das experiências sócioespaciais pósmodernas e de fenômenos correlatos como a fragilização de alguns Estados nacionais, da fluidez econômica e do hibridismo cultural (2011: p:1). E por fim, a autora argumenta que:

Na América Latina e Caribe, tomando a diáspora africana como perspectiva, o termo ainda pode ser concebido por um terceiro prisma: como Movimento Social. E são as mulheres afrodescendentes deste território, as protagonistas, as vozes que empreendem esse processo, mulheres que nos últimos vinte anos se organizaram de múltiplas formas e que, a cada ação política que desenvolvem, vêm impondo diferentes territorialidades e estéticas, e politizando temas que até então estavam subalternizados e invisibilizados (p:1).

Assim, REIS (2011) assinala que são as mulheres que têm concentrado esforços significativos para denunciar e revelar as disparidades raciais e de gênero que atingem os povos afrodescendentes nas Américas, criando e articulando constantes canais de interlocução e trilhando caminhos que viabilizem o "romper fronteiras" e o estabelecimento de "parcerias e práticas estratégicas com a sociedade civil, com o executivo, o legislativo, o judiciário e com agências de cooperação nacional e internacional” procurando, assim, garantir a criação e implementação de políticas públicas que visem à promoção de mecanismos sociais que garantam a igualdade, equidade, e a justiça social (p. 2). A autora assinala ainda que este grupo de mulheres,

$$
\begin{aligned}
& \text { Constituem cada vez mais um } \\
& \text { movimento transnacional globalizado } \\
& \text { na região, reunido em torno de } \\
& \text { múltiplas identidades afro que, por sua } \\
& \text { vez, indicam a superposição de novas } \\
& \text { territorialidades, } \\
& \text { multiterritorialidades, ou ainda, } \\
& \text { transterritorialidades, mudanças } \\
& \text { espaços-temporais que produzem } \\
& \text { alteridade e solidariedade, mas } \\
& \text { também conflitos e distanciamentos } \\
& \text { (p. 2). }
\end{aligned}
$$

Com o objetivo de refletir sobre as questões apresentadas o artigo está dividido em duas partes. A primeira busca apresentar o que a história da Diáspora 
Africana (ou Negra) nas Américas revela sobre as condições sociais das mulheres negras. Na segunda parte procuramos refletir sobre a perspectiva racial de gênero das mulheres negras nas Américas. E por fim, tecemos breves considerações finais sobre a relevância da presença e ação das mulheres afrodescendentes no continente, através de suas ações políticas e produção de conhecimentos; e ainda sobre como estas questões devem influenciar de forma relevante nossas agendas de pesquisa.

\section{O Que a História da Diáspora} Africana (ou Negra) nas Américas revela sobre as condições sociais das Mulheres Negras?

É de extrema importância enfatizar como o processo de escravização nas Américas marcou de modo peculiar à experiência de opressão das mulheres afrodescendentes nesta região. Em entrevista realizada pela jornalista Mirian Leitão em 29/08/2014 para a Globo News, na Fundação Casa de Rui Barbosa, o Prof. e Historiador Manolo Florentino afirmou que:

O Brasil faz parte na sua origem do maior movimento migratório compulsório da história humana antes do séc. XIX, que é o tráfico de escravos da África para as Américas.
Foram 11 milhões de pessoas que chegaram vivas... . E desse total o Brasil recebeu em torno de 5 milhões, dos quais, 4 milhões entraram no séc. XVIII e no séc. XIX, portanto, na América não há uma civilização com uma raiz tão afro, e tão pouco há uma civilização onde a natureza, a face africana seja tão recente.

A constatação sobre o peso da presença dos povos africanos e os efeitos da escravidão negra no continente americano nos leva a pensar sobre algumas indagações, tais como, qual o significado de ser uma mulher negra nas Américas em seus vastos e distintos territórios? Que valor tem a vida destas mulheres? Que direitos lhes têm sido negados? E que demandas elas têm construído?

Neste sentido, a questão colocada por Sojourner Truth “Ain' I a woman?” (Não sou eu uma mulher?) é muito pertinente para buscar construir as respostas para questões tão atuais acerca das condições de vida das mulheres negras. A pergunta é o título de um discurso que TRUTH fez no século XVIII, em 1851, diante de uma grande plateia na Convenção de Mulheres em Akron, Ohio nos Estados Unidos da América. Seu questionamento conecta o passado e o presente no que se refere ao 
status atribuído às mulheres negras. Ele nos remete a reflexões sobre como os corpos das mulheres negras são vistos e tratados, e que seus corpos têm sido dispostos como mercadorias, como um negócio lucrativo desde o processo de escravização negra/ africana até os dias atuais como sinaliza a autora bell hooks ${ }^{4}$ (2016).

A questão colocada por TRUTH traz ainda, constatações importantes sobre o fato de que os processos de violação dos corpos destas mulheres foram naturalizados como parte de normas sociais e leis, como meios necessários para obtenção de lucros e benefícios advindos da exploração destas "mercadorias" (hooks, 2016). Violações tais como abusos e violências físicas e psicológicas: exploração sexual e reprodutiva, e estupro, exploração da força de trabalho nos espaços privados (domésticos) e públicos (plantações, rua).

As inquietações de TRUT revelam também que os efeitos destas violações são a precarização e deterioração das condições de vida e saúde, que se traduzem em vulnerabilidades sociais, tais como:

(a) A exclusão de direitos sociais, econômicos, culturais que dentre eles incluem: a saúde, alimentação, trabalho, moradia, transporte, lazer, segurança, previdência social, proteção à maternidade e à infância, assistência aos desamparados dentre outros previstos no Pacto Internacional dos Direitos Econômicos, Sociais e Culturais;

(b) O aumento da vulnerabilidade a certas doenças que são desencadeadas e/ou que se agravam com a falta de infraestrutura de saneamento básico, medidas de saúde educativas e preventivas;

(c) E a solidão e Isolamento político.

Assim, ainda que se reconheça que as mulheres negras nas Américas, sejam constituídas por um grupo diverso, plural em termos de aspectos socioculturais, políticos, socioeconômicos, geográficos, e também no que tange a suas orientações sexuais e de gênero, estas apresentam similaridades importantes no que se refere a vivenciarem um tipo de opressão que conjuga a intersecção entre a discriminação racial e de gênero. De modo que, não estou tentando dizer que estas mulheres negras são completamente semelhantes em suas formas de expressão social, pensamento e ação política, mas 
não há como negligenciar que as experiências de escravização (dominação e exclusão) dos povos africanos e afrodescendentes - criadas pelo racismo e o patriarcalismo (que produz as discriminações de gênero) e reguladas por meio do colonialismo e do capitalismo produziram nestes diversos contextos diaspóricos experiências de opressão similares para as mulheres negras. E tais realidades necessitam ser mais bem identificadas e compreendidas por nós pesquisadoras.

E por este motivo considero ser possível refletir sobre aqueles aspectos que aproximam a realidade de opressão destes grupos, bem como, obviamente, suas divergências. Deste modo, para esta reflexão nos debruçaremos sob suas similaridades. Mas como já salientei, é importante enfatizar que há diferenças importantes entre estes vários grupos, que podem e vão gerar necessidades, interesses e demandas distintas, que não devem ser negligenciados. E é preciso ressaltar, ainda, que as diferenças em muitos momentos, apesar de gerar conflitos, não têm necessariamente impedido que as mulheres negras nas Américas e em outras partes da Diáspora Africana trabalhem em conjunto, visando seu bem estar comum.
Assim, na busca por refletir sobre as questões que envolvem as similaridades destes grupos, é que indago: Como as experiências de gênero e raça vivenciadas pelas mulheres negras nas Américas se configuram?

As histórias do movimento de mulheres negras nas Américas está repleta de episódios significativos (ocorridos em espaços nacionais e transnacionais) que evidenciam a situação multifacetada do tipo de opressão a que este grupo está exposto, e que têm produzido drásticos efeitos sob suas condições de vida e status nas sociedades onde vivem.

Mulheres afrodescendentes em diferentes regiões das Américas sempre lutaram por reconhecimento dentro dos movimentos de mulheres e do movimento feminista (de origem branca eurocêntrica e norte americana), cuja proposta tomava "como referência a mulher branca, de classe média, urbana, heterossexual, e acadêmica” (CARDOSO, 2008: p.2). A mesma luta vai ocorrer junto ao Movimento e Comunidade Negros.

A análise da Afrodominicana Ochy Curiel (2003) nos oferece grande contribuição no que se refere a compreensão da vinculação entre a organização intelectual, social e política das mulheres Afrodescendentes e a articulação das categorias raça e gênero, 
mas também classe e sexualidade. Segundo a autora:

O Movimento de mulheres negras nasce articulando raça, gênero, classe, e sexualidade enquanto categorias políticas para explicar a realidade das mulheres negras frente ao racismo, sexismo, classismo, e o heterosexismo (minha tradução, p.1)

A literatura produzida no campo político e acadêmico por feministas afrodescendentes tem enfatizado a centralidade da intersecção de raça ${ }^{5}$, gênero, classe e sexualidade não só no que se refere à compreensão do status marginalizado e drásticas condições de vida a que as mulheres negras encontramse sujeitas, mas também no que diz respeito à elaboração de estratégias sociais e políticas que transformem estas circunstâncias. Segundo as feministas Jurema Werneck e Solange Dacach (2004), “as mulheres negras têm identificado que juntamente com o racismo, outras ideologias se colocam prejudicando o exercício delas de direitos de cidadania e o alcance das políticas públicas, tais como o sexismo e a lesbofobia (p. 9)”.

Em sua análise sobre "O impacto econômico do racismo e do sexismo sobre as mulheres afrodescendentes da América Latina e do Caribe" a ativista e intelectual negra da Costa Rica Epsy Campbell Barr (2003) enfatiza que,

O racismo contemporâneo é uma ideologia construída a partir de um modelo econômico liberal que tem suas raízes no processo de colonização e conquista dos continentes africano e americano, marcando seu início especificamente com o tráfico transatlântico de pessoas africanas que foram convertidas em escravas para o desenvolvimento e exploração dos recursos nas Américas (p. 2).

BARR (2003) revela que desde sua origem $o$ racismo tem sua base na estrutura econômica, construindo ideologicamente as justificações culturais e sociais para colocar o que se convencionou chamar de "raça" branca (ainda que hoje saibamos que raça em termos biológicos não existe), como protótipo do humano e como tal superior a todos os grupos étnico-raciais diferentes; particularmente as pessoas de descendência africana - definidas como "raça" negra - foram identificadas a partir deste lugar de 'menos humanidade'. E tal perspectiva foi utilizada para se construir o conhecimento e a história da América.

A autora argumenta ainda que o racismo estabeleceu relações econômicas e sociais que propunham um modelo de "desenvolvimento ocidental na América", 
cujo propósito era o da acumulação de enorme riqueza e a promoção de benefícios e bem estar para os homens brancos e em segundo termo para as mulheres brancas, "através da exploração da riqueza natural e do trabalho escravo de milhões de pessoas africanas homens e mulheres por mais de três séculos" (minha tradução, Barr, 2003: p.2). BARR (2003) também nos evidencia que "o racismo, e mais especificamente o modelo econômico racista", se constituiu por meio de outra "realidade econômica milenar, o sexismo, no qual os poderes e os recursos se encontram nas mãos dos homens, sendo as mulheres praticamente propriedade dos homens, assim como as casas, as terras e os cavalos" (minha tradução, p.2).

$$
\text { Portanto, para Epsy Barr (2003) “o }
$$

racismo, reafirma o sexismo e incorpora dentro dele as diferenças sexuais e a superioridade dos homens sobre as mulheres como uma característica inerente constitutiva de sua ideologia” (minha tradução, p.2). E nesta mesma lógica "o sexismo incorpora a diferenciação racial como uma categoria de estratificação”, produzindo uma hierarquização baseada "na diferenciação sexual e na distinção racial, que reafirma, o branco como protótipo do humano em contraposição aos negros que é sempre relacionado com o não humano, ou menos humano" (minha tradução: p.2).

Destarte, a partir desta perspectiva apresentada, a autora revela que "é impossível na atualidade compreender o racismo de maneira isolada do sexismo. Do mesmo modo, não se pode isolar as consequências sociais e culturais do racismo das consequências da estrutura racista sobre as condições particulares das mulheres afrodescendentes das Américas" (minha tradução: p.3).

Segundo Epsy Barr (2003) "não é possível fazer uma análise que diferencie de maneira tácita (silenciosa, subentendida, implícita, que não se exprime por palavras) os impactos do racismo, por um lado, e o do sexismo, por outro, sobre a vida das mulheres. Os limites entre um e outro (racismo e sexismo) são a maioria das vezes absolutamente invisíveis" (minha tradução: p.3).

BARR (2003) conclui suas análises argumentando que "uma compreensão mais assertiva da forma como o sexismo e o racismo interagem sobre as condições de vida das mulheres afrodescendentes só é possível a partir da compreensão das implicações econômicas do modelo de desenvolvimento implícita e explicitamente sexista e racista, que possui mecanismos que tem se sofisticado 
com o tempo, para excluir maiorias negras e indígenas" (minha tradução: p.3).

Finalmente, para lidar com a realidade de opressão identificada pelas autoras as mulheres afrodescendentes nas Américas, irão desenvolver estratégias e ações que têm como pano de fundo um cenário de lutas políticas e experiências muito similares e que permeiam a emergência de suas distintas e plurais coletividades femininas, e os quais tenho identificado como:

- Experiência da opressão;

- Conjunto de fatores que compõem o legado de lutas das mulheres negras contra a opressão;

- "O legado de luta contra o racismo, o sexismo, e a exploração de classe;

- A busca por voz ou a recusa das mulheres negras em manter-se silenciadas;" (APPIAH, 1999: p. 742)

- “A impossibilidade de separar a questão e a análise intelectual do ativismo político;" (APPIAH, 1999: p. 742$)$

- "O empoderamento no contexto da vida cotidiana;" (APPIAH, 1999: p. $742)$

- Intercâmbios Geográficos e Políticos entre as várias vertentes do Movimento de mulheres Negras nas Américas.
E para dar conta de compreender e intervir em suas realidades de opressão, intelectuais negras feministas e outras ativistas têm construído e se posicionado a partir de uma vasta produção de conhecimento por meio de um conjunto de teorias. A Teoria da Perspectiva ou do Ponto de Vista/ Standpoint theory; Patricia Collins (1989) apresenta a teoria standpoint como uma forma de capacitar grupos oprimidos, de valorizar as suas experiências, e de se construir um caminho que apontasse uma maneira de desenvolver uma "consciência de oposição" (citado por HARDING, 2004: p. 2).

A Teoria da Interseccionalidade /Intersectionality Theory foi utilizada por intelectuais como Patricia Collins (1989, 2000) e Kimberlé Crenshaw (1989). Esta constitui o estudo das interconecções entre formas ou sistemas de opressão, dominação ou discriminação. Feministas negras ativistas e acadêmicas têm argumentado que a experiência de ser uma mulher negra não pode ser simplesmente compreendida em termos do ser negra e do se mulher, considerados independentemente, mas ao contrário, esta experiência deve ser compreendida dentro de uma relação de interação onde cada opressão - racismo e sexismo - reforçam 
uma a outra. É uma teoria sociológica feminista que foi primeiramente desenvolvida por Kimberlé Crenshaw em 1989. Entretanto, é importante levarmos em consideração que as análises (e usos) sobre este conceito podem ser encontradas no século XIX. Assim, esta noção foi utilizada anteriormente por mulheres negras ativistas e acadêmicas em seus discursos políticos e estudos para caracterizar as experiências que as negras enfrentavam na sociedade. Podemos indicar como exemplo o ativismo de maria W. Sttewart t que em 1831 "desafiou as mulheres afro-amenricanas a rejeitarem as imagens negativas atribuídas à figura das mulheres negras, muito disseminadas naquele período, apontando que as opressões de raça, gênero, e classe eram as principais causas da pobreza entre elas (minha tradução)" (Collins, 2000: p. 1). Patricia Collins (2000) enfatizava que,

(...) Rejeitando modelos aditivos de opressão, os estudos sobre raça, classe, e gênero têm progredido consideravelmente desde os anos 80 . Durante essa década, as mulheres afro-americanas acadêmicas- ativistas, entre outras, demandavam por uma nova abordagem para a análise das experiências das mulheres negras. Argumentando que tais experiências eram definidas (moldadas) não apenas pela raça, mas também por sexo, classe social e sexualidade, obras como Women, Race and Class de Angela Davis (1981), “A Black Feminist Statement", elaborado pelo Combahee River Coletivo (1982), e Audre Lorde (1984) com o clássico volume de Sister Outside se constituem em trabalhos essenciais que exploraram as interconexões entre os sistemas de opressão. Trabalhos posteriores tiveram como objetivo descrever as diferentes dimensões dessa relação interligada, a exemplo do termos interseccionalidade cunhado por Crenshaw, 1991)" (minha tradução, p. 18).

Assim, a teoria da interseccionalidade sugere que tipos distintos de categorias biológicas, sociais e culturais, a exemplo de raça, gênero, classe, deficiências, orientação sexual, casta, dentre outros eixos de identidade atuam uns sobre os outros (interagem) em múltiplos e simultâneos níveis, acarretando situações de injustiça e desigualdade social. Através da abordagem interseccional é possível evidenciar que racismo, sexismo, homofobia ou lebofobia, não atuam independente um do outro.

O "Mulherismo"/ Womanism Theory é um termo feminista elaborado por Alice Walker (1983). É uma reação à 
percepção de que o "feminismo" não abarcava as perspectivas das mulheres negras. É um feminismo que deseja contemplar e expressar a diversidade, as diferenças entre estas mulheres). Seria uma abordagem quase idêntica ao "Black Feminism" (Feminismo negro). No entanto, segundo suas adeptas o Mulherismo não precisaria ser antecedido pela palavra "Black" (Negro), pois a palavra já se refere automaticamente as mulheres negras. A Mulherista seria alguém que ama as mulheres e valoriza sua cultura e poder presente no mundo. Esta abordagem direciona suas críticas aos aspectos racistas, classistas presentes no feminismo branco e se coloca contra ideologias que promovem o separatismo. Ela defende ainda, a inclusão dos homens negros enquanto parte importante da vida das mulheres negras, seja como filhos, amantes, ou outros membros da família. E por fim, o Mulherismo se refere ao reconhecimento e enaltecimento do poder sexual de mulheres negras reconhecendo ao mesmo tempo uma história de violência sexual. Esta perspectiva é frequentemente utilizada como um meio para analisar a literatura das mulheres negras, uma vez que marca o lugar onde a raça, classe, gênero e sexualidade se cruzam (minha tradução, A Femininst Theory Dictionary ${ }^{6}$ ).
Os Estudos do Feminismo AfroLatino-Americano desenvolvidos por Lélia Gonzalez entre as décadas de 70 e 80 , a exemplo da elaboração do conceito de Amefricanidade em 1980 pela autora, onde a partir de uma perspectiva pós-colonial busca refletir sobre as resistências de lutas dos povos colonizados - afrodescendentes e indígenas no continente americano (ver CARDOSO, 2004 e GONZALEZ, 2016).

Há ainda os Estudos de Gênero sobre a perspectiva não heretonormativa ${ }^{7}$ que fazem críticas aos modelos heteropatriarcais $^{8}$ de identidade, sexualidade, gênero a exemplo de intelectuais como Barbara Smith (1988), Combahee River Collective (2000), Audre Lord (1984a, 1984b, 1990), Jacque Alexander (1997), dentre outros.

Finalmente, podemos concluir o quão importante têm sido a produção de conhecimento das mulheres negras, no que se refere a elaboração de teorias e metodologias alternativas aos modelos clássicos, que possam da conta de desvelar e explicar realidades complexas de se apreender e investigar. Em busca de compreender os efeitos de processos de exclusão e marginalização social, estas mulheres acabaram por inventar novos caminhos epistemológicos, ferramentas teórico-metodológicas que lhes 
permitiram aferir e apreender situações subalternizadas.

\section{A perspectiva racial de gênero das mulheres negras nas Américas}

Em outro trabalho (SANTOS, 2009) chamava a atenção para o fato de que feministas e ativistas negras desenvolveram uma perspectiva racial de gênero acerca de sua situação social frente à situação de opressão que vivenciam em sociedade (CRENSHAW, 1995, 2000, 2002; WERNECK, 2001 e 2006, dentre outras). Quando enfatizo o termo racial de gênero, pretendo sinalizar que estas mulheres têm se referenciado nesse aspecto para afirmar que sua experiência de opressão "vai além de justapor raça e gênero" (p. 282). Mais especificamente argumento que,

(...) o termo tenta dar conta do tipo de opressão que elas têm sofrido, e, por conseguinte, identificar o tipo de ação política que essas mulheres compreendem ser necessária à melhoria da qualidade de vida delas, e da população negra. Assim, a perspectiva racial de gênero identifica (e denuncia) que a intersecção de raça e gênero produz situações de opressão, bem como demandas específicas, que são distintas daquelas produzidas pela atuação "somente" do racismo ou "somente" do gênero. Tal condição singular coloca as mulheres negras desprotegidas e em desvantagem social tanto do ponto de vista dos mecanismos de proteção contra a discriminação de gênero quanto do ponto de vista dos mecanismos de proteção contra a discriminação racial (p. 282).

Assim, compelidas ao enfrentamento desta realidade específica de opressão, as mulheres negras nas Américas têm se destacado quanto a promoção de ações anti-racistas fundamentais que têm demarcado a presença e contribuições destas para a melhoria da qualidade de vida de mulheres e populações afrodescendentes, não apenas na região, mas em todo o mundo. Um primeiro exemplo de ações anti-racista e anti-sexista produzidas pelas políticas geradas a partir das experiências das feministas negras (e movimento de mulheres negras como um todo) pode ser vislumbrado na atuação da Rede de Mulheres Afrolatino-Americana e Caribenha. Esta rede foi criada em 1992 a partir da necessidade de se confrotar a situação de exclusão vivida pelas mulheres negras na América Latina e no Caribe, e ainda pela necessidade trazida por estas mulheres de incidir de forma organizada a partir de uma visão regional sobre 
instâncias governamentais e de Estado no que se refere à elaboração e implementação de políticas públicas que atendam suas demandas e direitos. Os Encontros Feministas Latino-americanos e do Caribe que ocorrem desde a década de 80 também nos indicam a centralidade do trabalho de articulação destas mulheres: Bogotá, Colombia 1981; Lima, Peru, 1983; Bertioga, Brasil 1985; Taxco, México,1987; San Bernardo, Argentina, 1990; Costa do Sol/ San Diego, Costa Rica, 1993; Cartagena, Chile, 1996; República Dominicana, 1999 (ver Oliveira, 1998: p. 22).

Em particular, a atuação antiracista e Pensamento da ativista e intelectual afro-brasileira Lélia Gonzalez (1935-1994, nasceu em Belo Horizonte, Minas Gerais) no Movimento de Mulheres Negras Nacional e Transnacional assume grande significado no Brasil e na América Latina. Lélia atuou no movimento de mulheres entre as décadas de 1960 e 90. Foi uma grande liderança no contexto nacional $\mathrm{e}$ internacional na luta contra o racismo e o sexismo que impactava as condições de vida e status das mulheres negras brasileiras, e da diáspora. Como parte de seus esforços intelectuais e políticos Lélia Gonzalez elaborou o conceito de Amefricanidade, que foi pouco explorado entre os estudos sobre os impactos das discriminações raciais e de gênero. $\mathrm{O}$ conceito de Amefricanidade é uma "construção original de uma categoria transnacional capaz de abarcar a diáspora negra nas Américas. A partir deste conceito Lélia buscava discutir a experiência de opressão das mulheres afrodescendentes nas Américas com o sexismo e o racismo. Dedicada a revelar a importância do Feminismo Afro-Latino Americano, Lélia Gonzalez inaugura uma perspectiva de pensamento que propõe a descolonização do saber e da produção de conhecimento (Pons, 2014: p.965). Neste sentido, a autora atua como uma "Outsider Within" (forasteira de dentro), categoria trazida pela Afro-Americana feminista e socióloga Patricia Collins (1986). E como uma "Outsider Within" questiona a insuficiência das categorias analíticas das Ciências Sociais para explicar a realidade das mulheres negras (Pons, 2014: p. 965).

Por sua vez, os Encontros Feministas Brasileiros também têm se destacado na luta anti-racista e sexista nas Américas, e no mundo num sentido mais amplo: Fortaleza/ Ceará, 1979; Rio de Janeiro/RJ, 1980; Salvador/Bahia, 1981; Campinas/SP, 1982; Campinas/SP, 1983; São Paulo/SP, 1984; Belo Horizonte/MG, 1985; Nogueira/RJ, 1986; Garanhuns/PE, 1987; Bertioga/SP, 1989; Caldas 
Novas/GO, 1991; Salvador/BA, 1997 (ver

Oliveira, 1998: p. 22-23).

Outro exemplo de ação anti-racista e sexista produzida pelas políticas geradas a partir das experiências das feministas e outras ativistas negras no Brasil contra o racismo, se constitui no estabelecimento da Articulação de Mulheres Negras Brasileiras (AMNB). Esta articulação foi fundada em setembro de 2000 e é atualmente constituída de 23 organizações provenientes das diferentes regiões do Brasil. Criada com o objetivo inicial de permitir o protagonismo das mulheres negras durante o processo de realização da III Conferência Mundial contra o Racismo, Xenofobia e Intolerâncias Correlatas (África do Sul, 2002). Após a Conferência a AMNB passa a se dedicar ao monitoramento das recomendações e do Plano de Ação e a formulação de estratégias de desenvolvimento inclusivo para o Brasil, centradas na proteção e na promoção dos direitos; na geração de oportunidades no mundo do trabalho na cidade e no campo; na igualdade de tratamento na vida e no respeito à diversidade humana, sem racismo, sexismo, lesbofobia ou classismo seja para o Brasil ou para a América Latina (fonte: http://www.amnb.org.br/). Ativistas e intelectuais afro-brasileiras como Sueli Carneiro e Nilza Iraci (ONG Geledes),
Lúcia Xavier e Jurema Werneck (ONG CRIOLA), Simone Cruz (ONG ACMUN), Edna Roland, Vilma Reis, Cida Bento, dentre outras tem liderado a AMNB em suas incursões nacionais e transnacionais.

Durante a III Conferência Mundial contra o Racismo, Discriminação Racial, Xenofobia e Intolerâncias Correlatas, realizada em 2001 em Durban, África do Sul, as ações políticas das mulheres negras das Américas (e do Caribe) foram vitais no que se refere à mobilização local, regional e global de mulheres, bem como de vários outros atores sociais e instituições, no que se refere a construção de uma análise de como o racismo operava historicamente pelo globo. Esta reflexão permitiu que o racismo fosse discutido e compreendido em sua dimensão global, enquanto uma construção histórica que tem influenciado a produção, distribuição e reprodução da riqueza e do poder nas sociedades e entre as nações (BAIRROS, 2002; CRENSHAW 2002; CURIEL, 2003).

BAIRROS (2002) destacou “o diferencial representado pela participação das mulheres no processo da III Conferência Mundial contra o Racismo, Discriminação Racial, Xenofobia e Intolerâncias Correlatas, em Durban, África do Sul” (p. 169). Segundo a autora,

Como as demais conferências das Nações Unidas, a de Durban também 
foi precedida por uma série de eventos preparatórios nas diversas regiões do mundo. Estes visavam mapear as distintas formas de racismo, identificar os grupos étnicos e raciais mais sujeitos aos efeitos de sua manifestação, como também propor ações aos Estados-membros e aos órgãos das Nações Unidas encarregados dos tratados internacionais (p. 169-170).

Assim, mobilizações como estas trouxeram para o centro do ativismo negro duas dimensões importantes da ação anti-racista: (1) a ação política produzida a partir da institucionalização de uma perspectiva de pensamento das mulheres negras alavancada dentro dos espaços da academia, a exemplo dos estudos gerados por Kimbérle Crenshaw e Ochy Curiel; e (2) a ação produzida pelas políticas que se originaram a partir das experiências do movimento social destas mulheres contra o racismo, a exemplo do surgimento da AMNB (Articulação de Mulheres Negras Brasileiras), e Rede de Mulheres Afro-latino-Americana e Caribenha.

No que se refere ao desenvolvimento de ações anti-racistas a partir da academia - da produção de conhecimento científico - os estudos de Kimberlé Crenshaw ${ }^{2}$ acerca da interseccionalidade

(também

conceitualizado por afro-americanas nos anos 70 e 80, em especial bell hooks, Patricia Collins) representaram na Conferência de Durban em 2001 instrumentos de análise fundamentais para investigar os efeitos do racismo e de sua interseção com outros sistemas de dominação, tais como gênero e classe, nas condições de vida e status das mulheres negras, e outras mulheres não-brancas; tanto o campo acadêmico quanto o movimento de mulheres, sobretudo as não-brancas beneficiaram-se grandemente das análises de Crenshaw. Esta ação possibilitou que as feministas afrodescendentes de distintas regiões geográficas da Diáspora apresentassem e discutissem suas experiências com o racismo e sua intersecção com o sexismo, bem como suas estratégias e políticas adotadas no confronto deste sistema de dominação.

Segundo BAIRROS (2002) o tex to de Crenshaw foi originalmente apresentado em um dos eventos preparatórios para a Conferência de Durban: a Reunião de Especialistas, ocorrida em novembro de 2000, na Croácia. Em uma assertiva incursão ao tema da interseccionalidade, a autora assinalou as possibilidades de pensar os aspectos raciais da discriminação de gênero, 
sem perder de vista os aspectos de gênero da discriminação racial. A partir de uma avaliação acerca das limitações das interpretações no que tange aos "discursos correntes de defesa dos direitos humanos", CRENSHAW trouxe para discussão "uma metodologia de análise da subordinação interseccional como meio de eliminar as brechas desses discursos, através das quais tendem a desaparecer os direitos das mulheres que sofrem múltiplas opressões" (p. 169-170).

Da mesma forma, os estudos de Ochy Curiel $^{3}$ trazem para a discussão aportes teóricos e políticos do feminismo anti-racista no cenário transnacional, a perspectiva das lésbicas negras feministas, demonstrando a problemática da intersecção entre $o$ racismo e $o$ heterosexismo que produz um tipo de opressão ainda mais específica para mulheres lésbicas negras.

Por fim, retomando o papel central que as afrodescendentes tem protagonizado nas Américas, observamos que suas ações tanto nos espaços do movimentos social, quanto nos espaços acadêmicos estas têm buscado desenvolver agendas políticas que efetivas na luta antiracista e sexista. E ainda, que haja, muito trabalho pela frente em termos de garantias de direitos para os afrodescendentes, em especial as mulheres, estas agendas políticas têm de algum modo compelindo as sociedades nas regiões das Américas a promoverem mudanças significativas para a melhoria da qualidade de vida destas populações.

\section{Considerações Finais}

O presente artigo buscou refletir sobre uma perspectiva da história intelectual da diaspora negra oferecendo uma análise sobre a ação política e o pensamento das mulheres negras nas Américas, frente às distintas dinâmicas sociais que têm marcado as experiências de opressão deste grupo. E buscou ainda, apresentar diferentes experiências de enfrentamento dos processos de subalternização e exploração destes grupos. Como enfatiza REIS (2011) as mulheres afrodescendentes nas Américas,

Têm sido as protagonistas, as vozes ao longo dos últimos vinte anos que vêm impondo diferentes mudanças na estrutura das sociedades constituintes destas regiões e politizando temas que até bem pouco tempo então estavam subalternizados e invisibilizados. (p.1)

Concluímos afirmando a importância da existência e atuação destes movimentos nas regiões das Américas, pois estes nos tem nos obrigado a pensar novas agendas 
em termos de ação política, bem como no que se refere as demandas de pesquisa sobre os movimentos de mulheres. Como enfatiza REIS (2011) é fundamental que incorporemos em nossas propostas de pesquisa "o empoderamento e protagonismo dessas mulheres como um movimento diaspórico, constituído como movimento social e dotado de uma estética de ação que se configura cada vez mais na forma de redes, transnacionalmente (Reis, 2010: p1)". Este se constitui num projeto de pesquisa ético, fascinante, e promissor em termos do fomento a mudanças sociais positivas no que se refere a construção de caminhos que permitam a visibilidade das lutas, legados, e contribuições que estas mulheres têm oferecido as sociedades das regiões das Américas.

\section{NOTAS}

1 Professora Adjunta da Universidade do Estado do Rio de Janeiro (UERJ), na Faculdade de Educação, Departamento de Ciências Sociais e Educação. Professora permanente do Programa de Pós-Graduação em Educação, Cultura e Comunicação em Periferias Urbanas da Faculdade de Educação da Baixada Fluminense/FEBFUERJ; e Pesquisadora do Núcleo de Estudos Afrobrasileiros da UERJ. Possui Pós-doutorado em Raça, Gênero e Política Pública, pelo Hubert H. Humphrey Institute of Public Affairs, University of Minnesota (2008-2009). É PhD. em Antropologia pela University of Texas at Austin (2008); e mestre em Sociologia com concentração em Antropologia pela Universidade Federal do Rio de Janeiro (2000).

2 Os termos mulheres negras, mulheres afrodescendentes serão utilizados neste trabalho como sinônimos.

${ }^{3}$ Os termos Diáspora Africana e Diáspora Negra serão utilizados como sinônimos.

${ }^{4}$ A autora bell hooks assina seus textos com letras minúsculas. É uma posição política contra os cânones da escrita acadêmica em seus termos clássicos.

5 O termo raça é compreendido e utilizado neste artigo como uma categoria socialmente construída e de natureza política para assinalar a existência de ideologias e práticas de opressão vinculadas a este que se constituem em realidades simbólicas e concretas que afetam as condições de vida e status social das mulheres negras, a exemplo, do racismo e a discriminação racial. Sua utilização para fins de análises acerca de pertencimento biológico ou genético foi considerada equivocada pela comunidade científica em suas diversas áreas do conhecimento.

6 Minha tradução, trecho disponível em: https://afeministtheorydictionary.wordpress.com/ 2007/07/17/womanism/ . Acesso em: 26/06/ 2016.

7 É um termo utilizado nas discussões sobre gênero e sociedade, principalmente dentro do campo da teoria crítica, da teoria de relações de gênero, e da teoria 'queer' (envolve os estudos acerca da sexualidade e a crítica ao heterosexismo). $\mathrm{Na}$ teoria das relações de gênero e da teoria 'queer', o conceito de heteronormatividade é compreendido como o reforço e institucionalização de certas crenças difundidas por muitas instituições sociais e também pelas políticas sociais. Dentre estas crenças estão: a ideia de que os seres humanos estão circunscritos à duas categorias distintas e ao mesmo tempo complementares - macho e fêmea; 
que relações sexuais e maritais são normais apenas entre pessoas de diferentes sexos; que cada sexo possui papéis naturais definidos. Este conceito critica ainda a crença e idéia de que a heterosexualidade é a única forma de orientação sexual normal (Ver Cohen).

${ }^{8}$ Basicamente este conceito tem sido utilizado por estudiosos e pesquisadores no campo dos estudos de gênero e sexualidade para descrever a intersecção (ou a ação conjunta) do heterosexismo com o patriarcalismo. A autora Jacqui Alexander (1997) demonstra em seus estudos que o heteropatriarcado contitui-se numa estrutura poderosa que tem sido utilizada pelo estado para propagar a dominação. A autora argumenta ainda que este conceito é extremamanete útil em continuar propagando a herança e modelos coloniais de exploração e subordinação; neste sentido as mulheres não-brancas (negras, indígenas, asiáticas, etc) têm sido grandes vítimas (p. 65).

9 Crenshaw, Kimberle. (2002). "Documento para

o Encontro de Especialista em Aspectos da Discriminação Racial relativos ao Gênero. Estudos Feministas, 171. 1/2002.

${ }^{10}$ Curiel, Ochy. (2003). Identidades Esencialistas o Construccion de Identidades Politicas: El dilema de las feministas negras. Journal Creatividad Feminista(ww.creatividadfeminista.org/articulos/f em_2003_negras.htm).

\section{REFERÊNCIAS BIBLIOGRÁFICAS}

ALEXANDER, Jacqui. Erotic Autonomy as a Politics of Decolonization: An Anatomy of Feminist and State Practice in the Bahamas Tourist Economy. In: Feminist Genealogies, Colonial Legacies, Democratic Futures. M. Jacqui, 1997.

APPIAH, Kwame A. and GATES, Henry L. Jr. Africana: The Encyclopedia of the African and African American Experience. New York: Civitas Book, 1999.
BARR, Epsy Campbell. El impacto económico del racismo y sexismo sobre las mujeres afrodescendentes de América Latina y el Caribe. Seminario Pobreza y Exclusion de los Pueblos y Mujeres Afrodescendentes, 2003, La Paz.

BAIRROS, Luiza. "III Conferência Mundial contra o Racismo." Dossiê: Apresentação. Estudos Feministas: Volume $10-\mathrm{n}^{\circ} 1-2002,169-170$.

bell hooks Institute. Moving Beyond Pain. May 9, $2016 . \quad$ Disponível em: http://www.bellhooksinstitute.com/blog/2016/5 /9/moving-beyond-pain . Acesso em: 21/05/2016.

CARDoso, Cláudia Pons. História das mulheres negras e pensamento feminista negro: algumas reflexões. Fazendo Gênero 8 - Corpo, Violência e Poder. Florianópolis, de 25 a 28 de agosto de 2008.

Cláudia Pons. Amefricanizando o feminismo: o pensamento de Lélia Gonzalez. Estudos Feministas, Florianópolis, 22(3): 320, setembro-dezembro/2014.

COLLINS, Patricia Hill. "Learning from the outsider within: the sociological significance of black feminist thought". Social Problems, v. 33, n. 6, p. 14-32, Oct./Dec. 1986.

Patricia H.. Black Feminist Thought: Knowledge, Consciousness, and The Politics of Empowerment. New York: Routledge, 2000.

COMBAHEE RIVER COLLECTIVE. "A Black Feminist Statement (p. 261-270)." The Black Feminist Reader. Ed. Joy and T. Denean SharpleyWhiting James. vols. Oxford: Blackwell, 2000.

COHEN, Cathy J. Deviance as resistance: A new research agenda for the study of Blacks. Du Bois Review: Social Science Research on Race, 1 (1), 27-45, 2004 .

CRENSHAW, Kimberle. Mapping the margins: intersectionality, identity, politics, and violence against women of color. In: __ et al. Critical race theory: key writings that formed the movement. New York: The New Press, 1995.

Demarginalizing the intersection of race and sex: a black feminist critique of antidiscrimination doctrine, feminist theory and antiracist politics. In: JAMES, Joy; SHARPLEYWHITING, T. Denean (Eds.). The black feminist reader. Oxford/Malden, Mass: Blackwell, 2000. 
Documento para o Encontro de Especialistas em Aspectos da Discriminação Racial relativos ao Gênero. Revista Estudos Feministas, v. 10, n. 1, p.171-188, 2002.

GONZALEZ, Lélia. Por um feminismo Afrolatino-americano. Caderno de Formação Política do Círculo Palmarino $n$. 1. Batalha de Ideias. AfroLatinoAmérica, Brasil, 2011. Disponível em : http://disciplinas.stoa.usp.br/pluginfile.php/2710 $77 / \mathrm{mod}$ resource/content/1/Por\%20um\%20femi nismo\%20Afro-latino-americano.pdf . Acesso em: 22/05/2016.

HARDING, Sandra. The Feminist Standpoint Theory Reader. New York: Routledge, 2004.

LORDE, Audre. Sister Outsider: Essays \& Speeches. Freedom,CA: The Crossing Press. The Crossing Press Feminist Series, 1984a.

"The Uses of the Erotic: The Erotic as Power." Freedom,CA: The Crossing Press. The Crossing Press Feminist Series, 1984b.

"I Am Your Sister: Black Women Organizing Across Sexualities," p. 321-325. In: Making Face, Making Soul/Haciendo Caras: Creative and Critical Perspectives by Feminists of Color. Edited by Gloria Anzaldua. San Francisco: Anna Lute, 1990.

OLIVEIRA, Fátima. Oficinas: Mulher Negra $e$ Saúde. Belo Horizonte: Mazza, 1998.
REIS, Marilise L. M. R. A Diáspora e o Movimento Social das Mulheres Afrodescendes das Américas. XI Congresso Luso Afro Brasileiro de Ciências Sociais. Diversidades (Des)igualdades. Salvador, 07 a 10 de agosto de 2011. Universidade Federal da Bahia (UFBA) - PAF I e II, Campus de Ondina.

SANTOS, Sônia Beatriz dos. As ONGs de mulheres negras no Brasil. Sociedade e cultura, Vol. 12, Núm. 2, julio-dezembro, 2009, pp. 275-288.

SMITH, Barbara. (1998). The Truth That Never Hurts: Writings on Race, Gender, and Freedom. New Brunswick: Rutgers University Press.

TRUTH, Sojourner. AIN'T I A WOMAN ?. GENERAL WOMEN \& FEMINISM. Delivered 1851 at the Women's Convention in Akron, Ohio. Disponível em:

http://www.feminist.com/resources/artspeech/ge nwom/sojour.htm . Acess in: 21/05/2016.

WALKER, Alice. (1983). In search of our mothers' gardens : womanist prose. 1st ed. San Diego : Harcourt Brace Jovanovich.

WERNECK, Jurema. A vulnerabilidade das mulheres negras. Jornal da Rede Saúde, n. 23, p.1-9, 2001

Incorporação das dimensões de gênero e de igualdade racial e étnica nas ações de combate à pobreza e à desigualdade: a visão da Articulação de Organizações de Mulheres Negras Brasileiras. Rio de Janeiro: AMNB, 2006.

\section{POLITICAL ACTION AND BLACK WOMEN'S THOUGHT IN THE AMERICAS: A PERSPECTIVE ON THE AFRICAN DIASPORA}

ABSTRACT: THIS ARTICLE REFLECTS ON A PERSPECTIVE OF THE INTELLECTUAL HISTORY OF THE BLACK DIASPORA FROM THE BLACK WOMEN'S POLITICAL ACTION AND THOUGHTS IN THE AMERICAS, IN THE FACE OF DIFFERENT SOCIAL DYNAMICS THAT HAVE MARKED THE OPPRESSIVE EXPERIENCES OF THIS GROUP. AND IT ALSO DEMANDS AND PRESENTS DIFFERENT COPING EXPERIENCES OF SUBORDINATION PROCESSES AND OPERATION OF THESE GROUPS. IT IS A HISTORY MARKED BY GENEALOGIES, POLITICAL ACTION, AND THE PRODUCTION OF KNOWLEDGE. IN ORDER TO REFLECT ON THE 
ISSUES PRESENTED IN THE ARTICLE IT IS DIVIDED INTO TWO PARTS. THE FIRST SEEKS TO PRESENT WHAT tHE HISTORY OF THE AFRICAN DIASPORA IN THE AMERICAS REVEALS ABOUT THE SOCIAL CONDITIONS OF BLACK WOMEN. IN THE SECOND PART WE tRY TO REFLECT ON THE RACIAL GENDER PERSPECTIVE OF BLACK WOMEN IN THE AMERICAS. AND IN THE CONCLUSION, WE WEAVE BRIEF REFLECTION ON THE IMPORTANCE OF THE PRESENCE AND ACTION OF WOMEN OF AFRICAN DESCENT ON THE CONTINENT, THROUGH ITS POLITICAL ACTION AND KNOWLEDGE PRODUCTION, AND HOW THESE ISSUES MUST INFLUENCE OURS SCHOLARSHIP AGENDA.

KEY-WORDS: BLACK WOMEN; POLITICAL ACTION; KNOWLEDGE PRODUCTION; ANTI-RACISM, ANTI-SEXISM; AFRICAN DIASPORA IN THE AMERICAS

\section{ACTION POLITIQUE ET LA PENSEE DES FEMMES NOIRES DANS LES AMERIQUES: UN POINT}

\section{DE VUE SUR LA DIASPORA AFRICAINE}

RÉSUMÉ: CET ARTICLE SE PROPOSE A FAIRE UNE REFLEXION SUR UNE PERSPECTIVE DE L'HISTOIRE INTELLECTUELLE DE LA DIASPORA NOIRE DE L'ACTION POLLTIQUE ET SUR LA PENSEE DES FEMMES NOIRES DANS LES AMERIQUES, FACE AUX DIFFERENTES DYNAMIQUES SOCIALES QUI ONT MARQUE LES EXPERIENCES D'OPPRESSION DE CE GROUPE. ON CHERCHE EGALEMENT a PRESENTER DIFFERENTES EXPERIENCES D'AFFRONTEMENT DES PROCESSUS DE SUBORDINATION

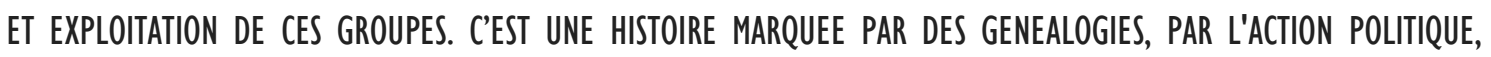

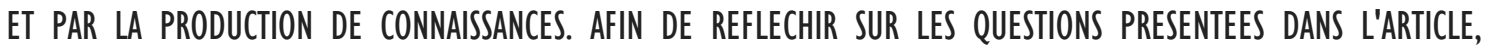
CELUI-CI EST dIVISE EN DEUX PARTIES. La PREMIERE VISE A PRESENTER CE QUE L'HISTOIRE DE LA DIASPORA AFRICAINE DANS LES AMERIQUES REVELE SUR LES CONDITIONS SOCIALES DES FEMMES NOIRES. DANS LA DEUXIEME PARTIE, ON ESSAIE DE REFLECHIR SUR LA PERSPECTIVE RACIALE DE GENRE DES fEMMES NOIRES DANS LES AMERIQUES. ET COMME CONCLUSION, ON TISSE UNE BREVE REFLEXION SUR L'IMPORTANCE DE LA PRESENCE ET DE L'ACTION DES FEMMES D'ASCENDANCE AFRICAINE SUR LE CONTINENT A TRAVERS LEUR ACTION POLITIQUE ET LEUR PRODUCTION DE CONNAISSANCE, ET ON DEMANDE COMMENT CES QUESTIONS DOIVENT INFLUENCER NOS PROGRAMMES DE RECHERCHE.

MOTS-CLÉS: FEMMES NOIRES; ACTION POLITIQUE; PRODUCTION DE CONNAISSANCES; ANTI-RACISME; ANTI-SEXISME; DIASPORA AFRICAINE DANS LES AMERIQUES 